\title{
Structural Study of Fucoidan from the Brown Seaweed Hizikia fusiformis
}

\author{
Riki ShIroma ${ }^{1}$, Teruko Konishi ${ }^{2}$, Shuntoku UeCHI ${ }^{2}$ and Masakuni TAKо ${ }^{2 *}$ \\ 1 The United Graduate School of Agricultural Sciences, Kagoshima University, 1-21-24 Korimoto, Kagoshima 890-0065, Japan \\ ${ }^{2}$ Department of Bioscience and Biotechnology, University of the Ryukyus, 1 Senbaru, Nishihara, Okinawa 903-0213, Japan
}

Received April 13, 2007; Accepted January 7, 2008

We investigated the structure of fucoidan from Hizikia fusiformis. Using DEAE-Sepharose column chromatography, fucoidan was fractionated into four groups. F4, main fraction of fucoidan, contained 38 $\%(w / w)$ of ester sulfate and had the simplest sugar component (L-Fuc: D-Gal=7:3). The structure of F4 was discussed using de-sulfation, 2D-NMR and methylation analysis and proposed as

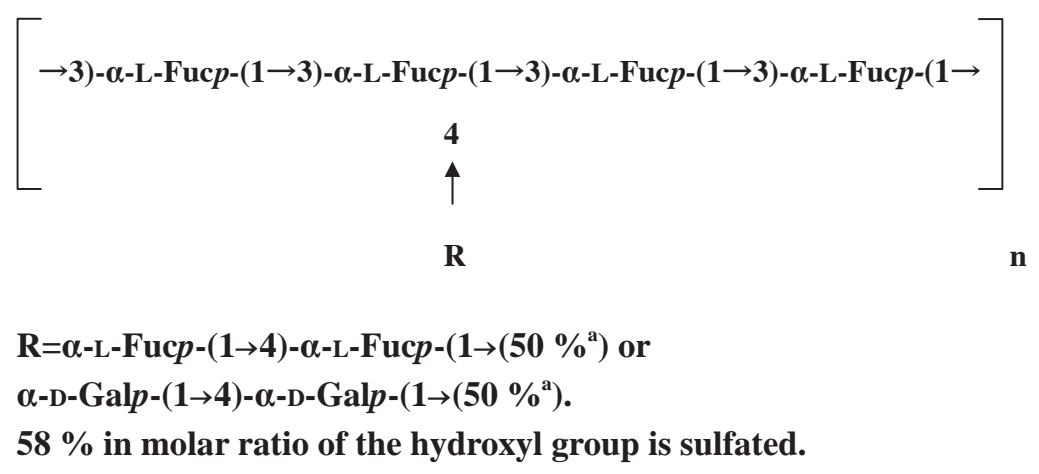

Keywords: fucoidan, Hizikia fusiformis, brown seaweed, de-sulfation, 2D-NMR, methylation

\section{Introduction}

Fucoidan, a cell-wall matrix polysaccharide in brown seaweed and some echinoderms, is composed of $\alpha$-L-fucose and ester sulfate, including minor amounts of D-Gal, D-Man, D-Xyl, D-Glc, D-GlcA and acetic acid. Fucoidans have been extensively investigated because of their various biological activities as an anticoagulant (Chevolot et al., 1999; Doane and Whistler, 1963; Nagumo and Nishino, 1996), antitumor (Itoh et al., 1993), antiviral agent (Baba et al., 1988; Ponce et al., 2003) and inhibitor of Helicobacter pylori infection (Shibata et al., 2003), and these activities differ according to linkage pattern, content of ester sulfate, sugar component and molecular weight (Berteau and Mulloy, 2003). It is also important to elucidate the structure of fucoidans to understand the interactions between their structure and biological activities. Recently, the structure of fucoidan from the brown seaweed has been identified using 2D-NMR or electrospray ionization mass spectrometry (ESI-MS) techniques (Bilan et

\footnotetext{
*To whom correspondence should be addressed.

E-mail: tako@agr.u-ryukyu.ac.jp
}

al., 2002; Chizhov et al., 1999; Daniel et al., 2007), although there is structural diversity.

In this study, Hizikia fusiformis, which is utilized for food material mainly in Japan and South Korea, was used for structural elucidation. Various reports have already addressed the preliminary characterization (Nishide et al., 1987; Nishino and Nagumo, 1987; Shiroma et al., 2003) and anticoagulant activity (Dobashi et al., 1989) of fucoidans from $H$. fusiformis, as well as the structure of a $H$. fusiformis fucoidan containing a fucose-free core (Li et al., 2006). However, the structure of fucoidan containing high-fucose and ester sulfate has not yet been reported. Here, we discuss the structure of fucoidan containing high-fucose and ester sulfate from $H$. fusiformis in an acidic extract.

\section{Materials and Methods}

Materials $H$. fusiformis used in this study was harvested in June 2002 from Yonabaru Town, Okinawa, Japan. The collected seaweed was washed with tap water and air-dried in an oven at $40{ }^{\circ} \mathrm{C}$ for $24 \mathrm{~h}$. The dried seaweed was then powdered using a mixer (MX-620G, Matsushita Electric In- 
dustrial Co., Ltd., Japan).

Isolation and fractionation of fucoidan from $\mathrm{H}$. fusiformis The isolation of crude fucoidan was carried out as previously reported (Shiroma et al., 2003). Briefly, dried seaweed (20 g) was suspended in $0.1 \mathrm{M} \mathrm{HCl}(200 \mathrm{ml})$ and stirred at room temperature for $6 \mathrm{~h}$. The suspension was filtered with a suction filter, and the filtrate was then neutralized with 0.5 $\mathrm{M} \mathrm{NaOH}$. The neutralized solution was concentrated and precipitated by the addition of 2 volumes of ethanol. The precipitate, crude fucoidan, was dried in vacuo and purified by cetylpyridinium chloride (CPC) precipitation. The CPCpurified fucoidan $(100 \mathrm{mg}$ ) was applied to the DEAE-Sepharose column (Cl- form, i. d.; 26(h; $260 \mathrm{~mm}$ ) and eluted with water followed by a liner gradient of $0 \rightarrow 3.5 \mathrm{M} \mathrm{NaCl}$ at a flow rate of $0.5 \mathrm{ml} / \mathrm{min}$. Fractions of $7 \mathrm{ml}$ were collected, and total carbohydrate and uronic acid contents were estimated using phenol (Dubois et al., 1956) and carbazole (Galambos, 1967) $-\mathrm{H}_{2} \mathrm{SO}_{4}$ reactions, respectively.

Chemical procedure and Liquid chromatography Acid hydrolysis was carried out by dissolving fucoidan in distilled water and adding sulfuric acid to a final concentration $2.0 \mathrm{M}$. The mixture was heated at $100{ }^{\circ} \mathrm{C}$ for $3 \mathrm{~h}$ and then neutralized with $\mathrm{BaCO}_{3}$. Neutral monosaccharide analysis of the fucoidan hydrolyzate was carried out by liquid chromatography on DX500 (Dionex Co., Ltd., USA) using a column of Carbopac PA 1 (i. d.; 4×h; 250 mm, Dionex Co., Ltd.) equilibrated with $3 \mathrm{mM} \mathrm{NaOH}$. Chromatography was carried out at a flow rate of $1 \mathrm{ml} / \mathrm{min}$ at $35^{\circ} \mathrm{C}$. Ester sulfate in fucoidan hydrolyzate, which had been treated by heating at $100{ }^{\circ} \mathrm{C}$ for $3 \mathrm{~h}$ in $2 \mathrm{M} \mathrm{HCl}$ solution, was determined by the $\mathrm{BaCl}_{2}$ gelatin method (Dodgson, 1961). The molecular weight of fucoidan was determined by a high-performance liquid chromatography (HPLC) (LC-6A; Shimadzu Co., Japan) on a column of TSKgel PW $\mathrm{XL}_{\mathrm{L}}$ (i. d.; 7.8×h; 300 mm, Tosoh Co., Japan) and detected with a refractive index detector RID-6A (Shimadzu Co., Japan) at room temperature. The column was eluted by $150 \mathrm{mM} \mathrm{NaCl}$ in $50 \mathrm{mM}$ phosphate buffer (pH 7.2) at a flow rate of $0.3 \mathrm{ml} / \mathrm{min}$. Pullulan P-5 (MW=0.59×10 $)$, P-20 (2.28 $\left.\times 10^{4}\right)$, P-100 $\left(11.2 \times 10^{4}\right)$ and P-400 $\left(40.4 \times 10^{4}\right)$ (Showa Denko Co., Japan) were used as the molecular weight standards.

De-sulfation Chemical desulfation of sample was carried out according to the method of Nagasawa et al. (1977). Sample (100 mg) was dissolved in distilled water (10 ml) and mixed with DOWEX $5 \mathrm{~W} \times 8\left(\mathrm{H}^{+}, 200-400\right.$ mesh). After neutralization with pyridine, the solution was lyophilized. The lyophilized pyridinium salt was dissolved in DMSO: $\mathrm{MeOH}(9: 1 ; \mathrm{v} / \mathrm{v}, 20 \mathrm{ml})$. The mixture was heated at $80{ }^{\circ} \mathrm{C}$ for $4 \mathrm{~h}$, and the desulfated product was dialyzed against distilled water and lyophilized.

NMR spectroscopy The spectra were recorded using a JNM-A500 (Nihondenshi Co., Ltd., Japan) at room temperature or $333 \mathrm{~K}$. The samples $(10 \mathrm{mg} / \mathrm{ml})$ were dissolved in $\mathrm{D}_{2} \mathrm{O}$, and chemical shifts are expressed in ppm relative to internal standard [3-(Trimethylsilyl) propionic-2, 2, 3, 3- $d_{4}$ acid sodium salt, as $0.00 \mathrm{ppm}]$. Two-dimensional spectra (COSY, HOHAHA, NOESY and HMQC) were recorded using the pulse programs supplied with the instrument.

Methylation analysis The methylation analysis was carried out by the modified method of Needs and Selvendran (1993). The NaOH-DMSO reagent was prepared by the addition of $\mathrm{MeOH}(0.2 \mathrm{ml})$ and DMSO $(6 \mathrm{ml})$ to a $50 \% \mathrm{NaOH}$ solution $(0.1 \mathrm{ml})$. The DMSO-layer was collected and backwashed with DMSO, then, DMSO (2 ml) was added. A solution of sample (3 $\mathrm{mg})$ in DMSO (2 ml) was mixed with $\mathrm{NaOH}-\mathrm{DMSO}$ reagent $(1 \mathrm{ml})$ and stirred at room temperature for $90 \mathrm{~min}$. To this mixture, $\mathrm{CH}_{3} \mathrm{I}(1 \mathrm{ml})$ was added and stirred at room temperature for $60 \mathrm{~min}$ in the dark. Next, distilled water $(4 \mathrm{ml})$ was added, and the mixture was dialyzed against distilled water and then evaporated in a vacuum to dryness. The above procedure was repeated two times. The methylated sample was extracted by the addition of $\mathrm{CHCl}_{3}$ (2 ml), and the $\mathrm{CHCl}_{3}$-layer was evaporated in a vacuum to dryness. The extract was added to 2 M TFA (2 ml) and hydrolyzed at $120{ }^{\circ} \mathrm{C}$ for $2 \mathrm{~h}$. The hydrolyzate was evaporated in a vacuum to dryness, and then $1 \mathrm{M} \mathrm{NH}_{4} \mathrm{OH}(100 \mu \mathrm{l})$ and $\mathrm{NaBH}_{4}(10 \mathrm{mg})$ in DMSO $(0.5 \mathrm{ml})$ was added. The reaction mixture was reduced at $40{ }^{\circ} \mathrm{C}$ for 90 min and then neutralized with AcOH $(100 \mu \mathrm{l})$. Next, 1-methylimidazol (100 $\mu \mathrm{l})$ and $\left(\mathrm{CH}_{3} \mathrm{CO}\right)_{2} \mathrm{O}(0.5 \mathrm{ml})$ was added, and the mixture was then acetylated at room temperature for $10 \mathrm{~min}$. The reaction was stopped by the addition of distilled water $(1.5 \mathrm{ml})$. Alditol acetates were extracted with $\mathrm{CHCl}_{3}$ and analyzed by GCMS on a QP-5000 (Shimadzu Co., Japan) using a DB-1 (i. d.; $0.25 \mathrm{~mm} \times 1$; $30 \mathrm{~m}$, Agilent Technologies, USA) capillary column. The temperature program was $150{ }^{\circ} \mathrm{C}$ for $5 \mathrm{~min}$ and then raised to $250{ }^{\circ} \mathrm{C}$ at $5{ }^{\circ} \mathrm{C} / \mathrm{min}$ and held for $5 \mathrm{~min}$. The carrier gas was He at flow rate of $1.2 \mathrm{ml} / \mathrm{min}$.

\section{Results and Discussion}

The CPC-purified fucoidan was obtained in yield of 1.3 $\%$ (w/w, dry material) and applied to the DEAE-Sepharose column using a linear gradient of $0 \rightarrow 3.5 \mathrm{M} \mathrm{NaCl}$ aqueous solution. Although $20 \mathrm{mM}$ Tris-HCl buffer (pH 7.3) was also used as the eluate, the elution profile was almost same as that of the former solvent system, and thus the elution with $0 \rightarrow$ $3.5 \mathrm{M} \mathrm{NaCl}$ aqueous solution was used.

The elution profile of the CPC-purified fucoidan was divided into four fractions based on the result of total carbohydrate analysis (Fig. 1). Each fraction was pooled, dialyzed against distilled water and lyophilized. The yields and chem- 


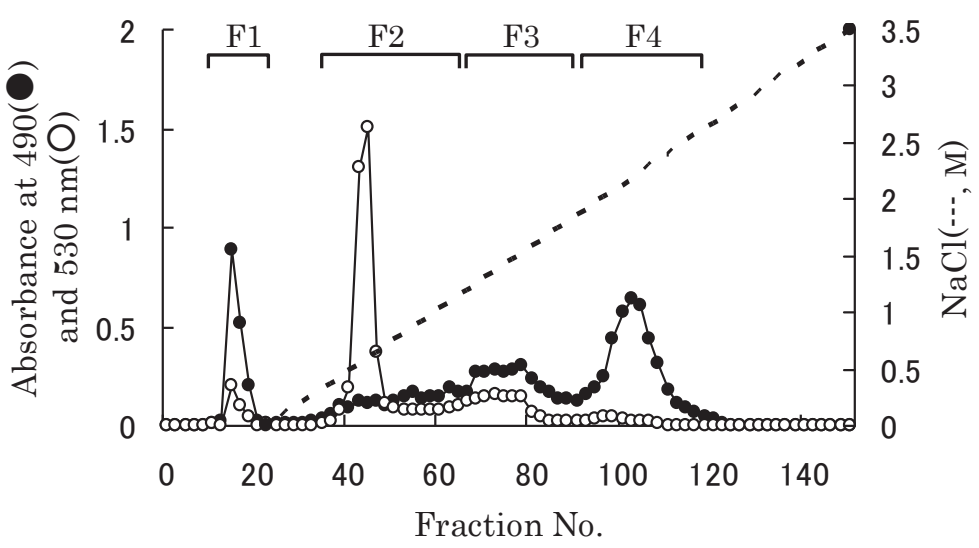

Fig. 1. Elution profile of the CPC-purified fucoidan on the DEAE- Sepharose column $(\phi 26 \times 260 \mathrm{~mm})$. The

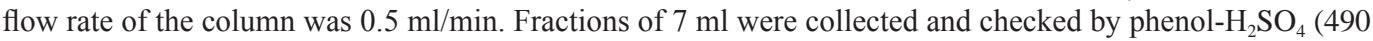
$\mathrm{nm})$ and carbazole- $\mathrm{H}_{2} \mathrm{SO}_{4}(530 \mathrm{~nm})$. The dotted line shows $\mathrm{NaCl}$ concentration.

Table 1. Yields and Chemical components of F1-F4 obtained by the DEAE-Sepharose column chromatography of the CPC-purified fucoidan.

\begin{tabular}{|c|c|c|c|c|c|c|c|c|}
\hline \multirow[b]{2}{*}{ Fraction } & \multirow{2}{*}{$\begin{array}{c}\text { Yield } \\
(\%, \mathrm{w} / \mathrm{v})\end{array}$} & \multicolumn{5}{|c|}{ Neutral monosaccharides(\%) } & \multirow{2}{*}{$\begin{array}{c}\mathrm{SO}_{3} \mathrm{Na} \\
(\%)\end{array}$} & \multirow{2}{*}{$\begin{array}{c}\text { MW } \\
\left(\times 10^{4}\right.\end{array}$} \\
\hline & & Fuc & Gal & Man & $\mathrm{Xyl}$ & Glc & & \\
\hline F1 & 13.3 & 44.8 & 36.1 & 7.0 & 9.8 & 2.3 & 19.3 & 35.2 \\
\hline $\mathrm{F} 2$ & 16.0 & 48.8 & 31.4 & 16.1 & 3.7 & - & 16.5 & 0.74 \\
\hline F3 & 10.8 & 56.7 & 31.4 & 5.9 & 4.7 & 1.3 & 33.0 & 29.0 \\
\hline $\mathrm{F} 4$ & 31.9 & 80.0 & 20.0 & - & - & - & 38.0 & 1.8 \\
\hline
\end{tabular}

ical compositions of the four fractions are shown in Table 1. F1, a through fraction of DEAE-Sepharose contained 19.3 $\%$ of ester sulfate and had a high molecular weight. Thus, it appeared to be a fucoidan fraction tightly-bonded with CPC. The ${ }^{1} \mathrm{H}$-NMR spectrum of F2, the highest uronic acid fraction, is shown in Fig. 2(A). As it is similar to that of alginate (Shiroma et al., 2007), it appears to be a low molecular weight soluble alginate fraction. In the ${ }^{1} \mathrm{H}-\mathrm{NMR}$ spectrum of F3, shown in Fig. 2(B), signals (2.0-2.2 ppm) arising from acetyl group were observed (Tako et al., 2000). Thus, F3 appears to be a fucoidan fraction containing acetylated sugars. We obtained the highest yield (31.9 \%) from F4, which had the simplest sugar composition (L-Fuc: $\mathrm{D}-\mathrm{Gal}=8: 2$, Table 1 ), and was thus used for structural elucidation.

The ${ }^{1} \mathrm{H}$ - and ${ }^{13} \mathrm{C}-\mathrm{NMR}$ spectra of $\mathrm{F} 4$ are shown in Fig. 3. Since these spectra were complex by their ester sulfates, and because it was difficult to elucidate the structure, F4 was de-sulfated as described in the Materials and Methods. Desulfated F4 (DeS-F4) was obtained in yield of $10.7 \%(\mathrm{w} / \mathrm{w})$ from native F4. As this was very small value compared with the theoretical value (about $60 \%$ ), it was considered that the main chain of F4 degraded during the solvolytic desulfation. Almost no ester sulfate was detected in DeS-F4 by the $\mathrm{BaCl}_{2}$
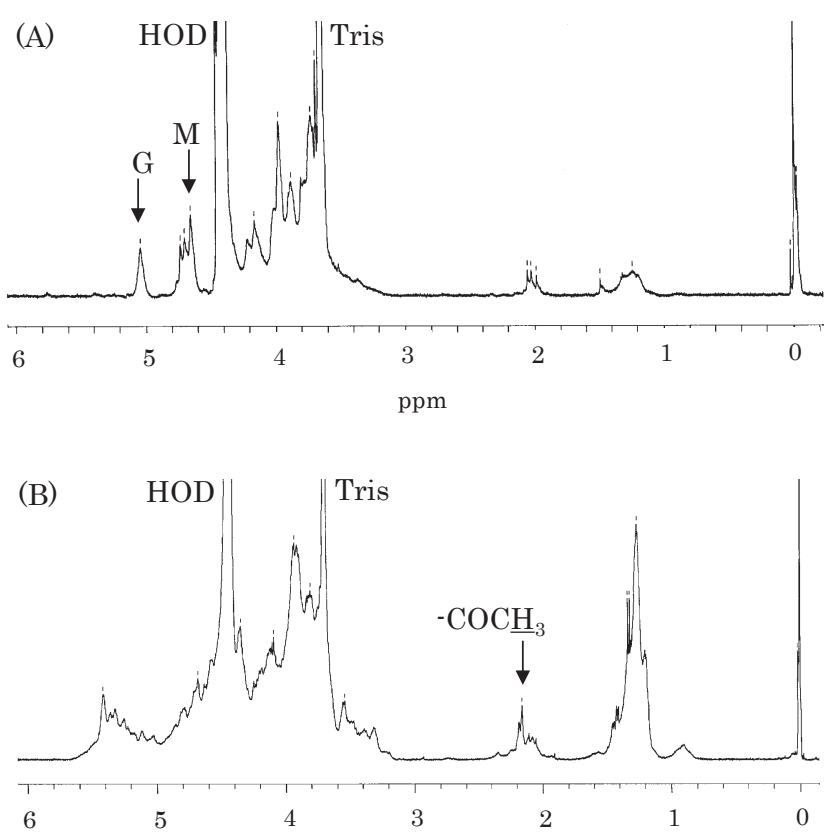

Fig. 2. ${ }^{1} \mathrm{H}-\mathrm{NMR}$ spectra of $\mathrm{F} 2(\mathrm{~A})$ and $\mathrm{F} 3(\mathrm{~B})$ in $\mathrm{D}_{2} \mathrm{O}$ at $60{ }^{\circ} \mathrm{C}$. Chemical shifts are referenced to internal TSP (0.00 ppm). M; anomeric proton of D-mannuronic acid, G; anomeric proton of L-guluronic acid. 


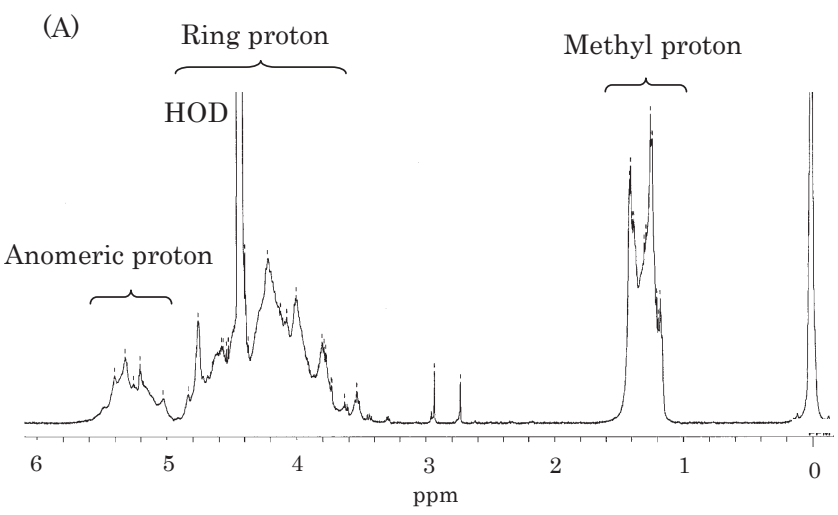

(B)

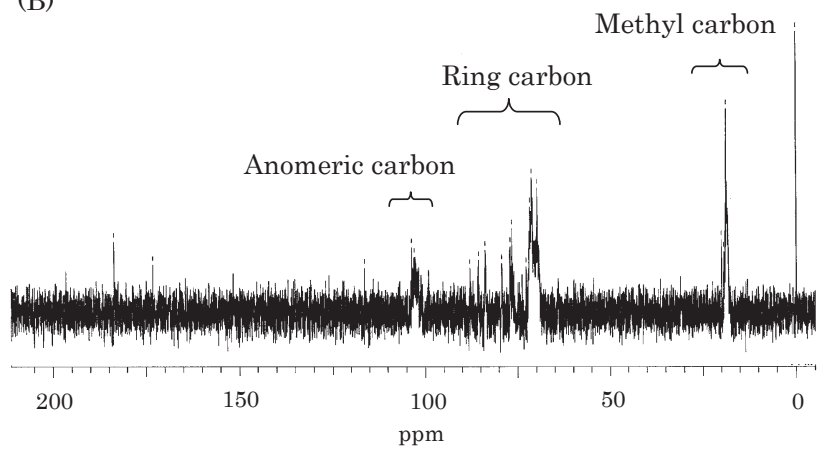

Fig. 3. ${ }^{1} \mathrm{H}$ (A)- and ${ }^{13} \mathrm{C}$ (B)-NMR spectra of $\mathrm{F} 4$ in $\mathrm{D}_{2} \mathrm{O}$ at $60{ }^{\circ} \mathrm{C}$. Chemical shifts are referenced to internal TSP (0.00 ppm).

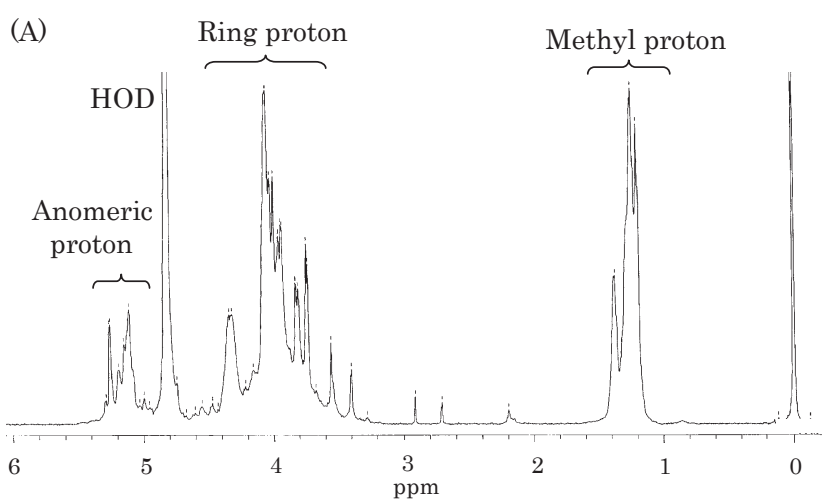

(B)

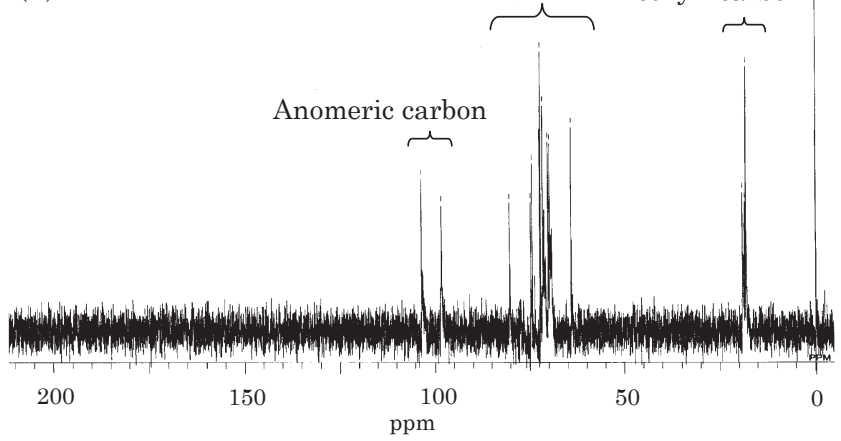

Fig. 4. ${ }^{1} \mathrm{H}$ (A)- and ${ }^{13} \mathrm{C}(\mathrm{B})-\mathrm{NMR}$ spectra of DeS-F4 in $\mathrm{D}_{2} \mathrm{O}$ at room temperature. Chemical shifts are referenced to internal TSP $(0.00$ ppm).

Table 2. ${ }^{1}$ Hand ${ }^{13} \mathrm{C}-\mathrm{NMR}$ data of DeS-F4.

\begin{tabular}{|c|c|c|c|c|c|c|c|}
\hline \multirow[b]{2}{*}{ Residues } & \multicolumn{6}{|c|}{${ }^{1} \mathrm{H}$ Chemical shifts (ppm) } & \\
\hline & $\mathrm{H} 1$ & $\mathrm{H} 2$ & $\mathrm{H}$ & $\mathrm{H} 4$ & $\mathrm{H} 5$ & $\mathrm{H} 6$ & \\
\hline$\rightarrow 3)-\alpha-\mathrm{L}-\mathrm{Fuc} p-(1 \rightarrow$ & $5.10 \vdots$ & 3.99 & $4.0 \leftrightarrows$ & $9 \quad 3.84$ & $4 \quad 4.31$ & 1.24 & \\
\hline$\rightarrow 3,4)-\alpha-\mathrm{L}-\mathrm{Fuc} p-(1 \rightarrow$ & 5.18 & 3.93 & - & 4.09 & 94.38 & 1.37 & \\
\hline$\rightarrow 4)-\alpha-\mathrm{L}-\mathrm{Fuc} p-(1 \rightarrow$ & $5.14 \vdots$ & 3.94 & $4.0 \leqq$ & $9 \quad 4.15$ & $5 \quad 4.36$ & 1.20 & \\
\hline \multirow[t]{3}{*}{$\rightarrow 4)-\alpha-\mathrm{D}-\mathrm{Gal} p-(1 \rightarrow$} & 5.26 & 3.81 & 3.9 & $4 \quad 4.05$ & $5 \quad 3.99$ & 3.74 & \\
\hline & \multicolumn{7}{|c|}{${ }^{13} \mathrm{C}$ Chemical shifts (ppm) } \\
\hline & $\mathrm{C} 1$ & $\mathrm{C} 2$ & & C3 & $\mathrm{C} 4$ & C5 & C6 \\
\hline$\rightarrow 3)-\alpha-\mathrm{L}-\mathrm{Fuc} p-(1 \rightarrow$ & 98.42 & - & & - & $\overline{-}$ & - & 18.17 \\
\hline$\rightarrow 3,4)-\alpha-\mathrm{L}-\mathrm{Fuc} p-(1 \rightarrow$ & 98.42 & - & & - & - & - & 18.48 \\
\hline$\rightarrow 4)-\alpha-\mathrm{L}-\mathrm{Fuc} p-(1 \rightarrow$ & 98.42 & - & & - & - & - & 18.17 \\
\hline$\rightarrow 4)-\alpha-\mathrm{D}-\mathrm{Gal} p-(1 \rightarrow$ & 103.49 & 71.6 & & 69.79 & 80.37 & 72.19 & 64.19 \\
\hline
\end{tabular}

gelatin method (Dodgson, 1961). The ${ }^{1} \mathrm{H}$ - and ${ }^{13} \mathrm{C}-\mathrm{NMR}$ spectra of DeS-F4 are shown in Fig. 4. As these spectra were simple enough, DeS-F4 was then used for 2D-NMR and methylation analyses.

The four signals, 5.10, 5.14, 5.18 and $5.24 \mathrm{ppm}$, were mainly observed in anomeric region of the ${ }^{1} \mathrm{H}-\mathrm{NMR}$ spectrum of DeS-F4. Using the COSY and HOHAHA experiments, the chemical shifts of ring protons of the four sugar residues were determined from these anomeric signals (Table 2). In the NOE spectrum of DeS-F4, the correlation peaks of $(1 \rightarrow 3)$ - or $(1 \rightarrow 4)$-linked sugar residues were not identified because the $\mathrm{H} 3$ and $\mathrm{H} 4$ region were still complex. However, it was reported by Bilan et al. (2006) that the H1' (the other sugar residue)/H3 and $\mathrm{H} 1^{\prime} / \mathrm{H} 4$ correlation peaks appear for $(1 \rightarrow 3)$-linked fucobioside fragments as well as $\mathrm{H} 1^{\prime} / \mathrm{H} 4$ and H1'/H6 peaks for $(1 \rightarrow 4)$-linked fucobioside fragments. In 
${ }^{1} \mathrm{H}$ chemical shift (ppm)

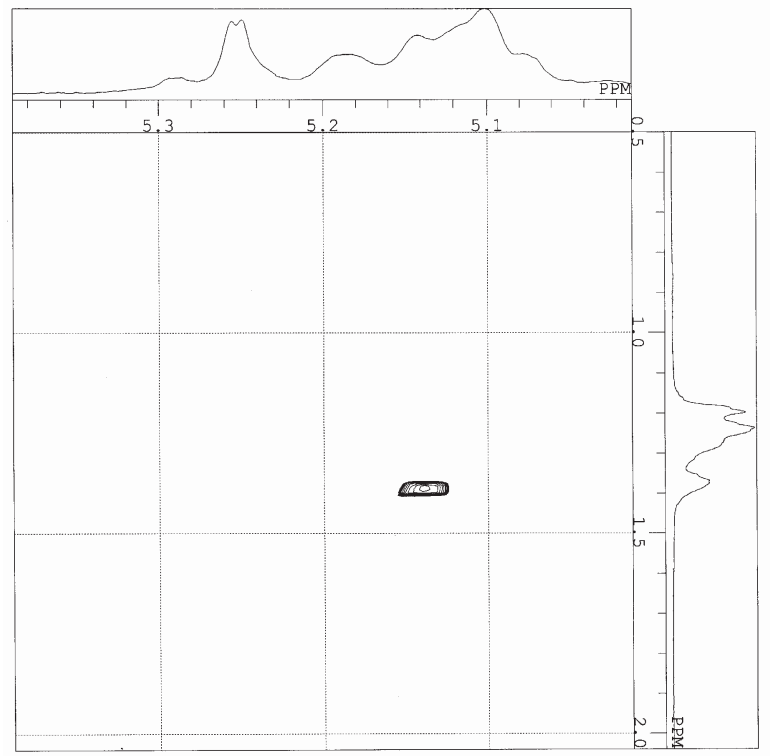

壱

Fig. 5. A part of NOESY spectrum containing $\mathrm{H} 1$ and $\mathrm{H} 6$ regions of DeS-F4 in $\mathrm{D}_{2} \mathrm{O}$ at room temperature. Chemical shifts are referenced to internal TSP $(0.00 \mathrm{ppm})$.

the $\mathrm{H} 1$ and $\mathrm{H} 6$ region of the NOE spectrum of DeS-F4 (Fig. 5), the correlation peaks of 5.14/1.37 ppm corresponding to $\mathrm{H} 1$ '/H6 was observed. Thus, the signal of $5.14 \mathrm{ppm}$ was assigned as $(1 \rightarrow 4)$-linked $\alpha$-L-fucopyranosyl residue. The independent signal, $5.26 \mathrm{ppm}$, was assigned as $(1 \rightarrow 4)$-linked $\alpha$-D-galactopyranosyl residue, compared with the data of Farias et al. (2000). In the HMQC spectrum of DeS-F4 (Fig. 6), although the assignments of ring carbon signals were not completed because the ring proton and carbon region were also complex, the correlation peaks of $\mathrm{H} 1 / \mathrm{C} 1$ and $\mathrm{H} 6 / \mathrm{C} 6$ were observed and assigned respectively (Table 2).

The methylated sugars and their relative molar ratio derived from DeS-F4 by GC-MS analysis are shown in Table 3. 2,4-di-O-methyl-fucitol, corresponding to $\rightarrow$ $3)-\alpha$-L-fucopyranosyl-( $1 \rightarrow$ residue, occupied about half of methylated sugars, and 2-O-methyl-fucitol, corresponding to $(3,4)-(-\mathrm{L}-$ fucopyranosyl-(1) residue, occupied about one third of the former residue. Compared these data with integral value of anomeric protons, the signals of 5.10 and 5.18 ppm were assigned as $\rightarrow 3$ )- $\alpha$-L-fucopyranosyl-( $1 \rightarrow$ and $\rightarrow$ 3,4)- $\alpha$-L-fucopyranosyl-( $1 \rightarrow$ residue, respectively.

From the above data, we proposed the structure of $\mathrm{F} 4$ from $H$. fusiformis in Fig. 7. The main chain of F4 is a (1 $\rightarrow 3$ )-linked $\alpha$-L-fucopyranosyl residue with branches, $\alpha$-Lfucopyranosyl-(1 $\rightarrow 4)$ - $\alpha$-L-fucopyranosyl- $(1 \rightarrow(50 \%)$ or $\alpha$-D-galactopyranosyl-( $1 \rightarrow 4)-\alpha$-D-galactopyranosyl-( $1 \rightarrow(50$ $\%)$, at $\mathrm{O}-4$ every four residues, and this core structure is sulfated to $58 \%$ of the hydroxyl group. The sulfated positions
${ }^{1} \mathrm{H}$ chemical shift (ppm)

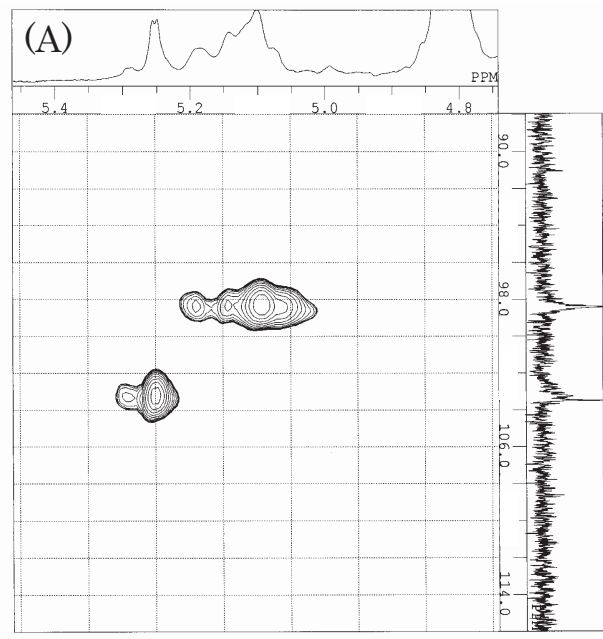

${ }^{1} \mathrm{H}$ chemical shift (ppm)

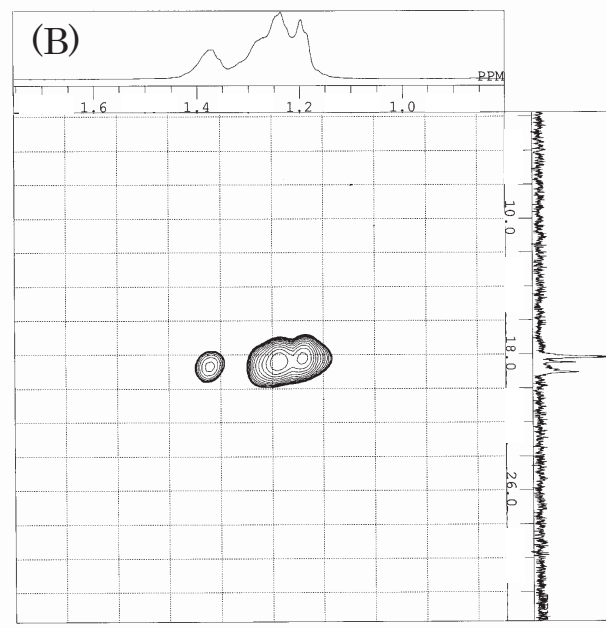

Fig. 6. Parts of $\mathrm{HMQC}$ spectra containing $\mathrm{H} 1 / \mathrm{C} 1$ (A) and $\mathrm{H6} / \mathrm{C} 6$ (B) regions of DeS-F4 in $\mathrm{D}_{2} \mathrm{O}$ at room temperature. Chemical shifts are referenced to internal TSP (0.00 ppm).

were not determined because of incomplete methylation of native F4. Clear evidence that galactosyl residue is attached to the main chain was also not obtained. Although our data did not agree with the findings of Nishino et al. (1994), Dobashi et al. (1989) reported that fucoidan from $H$. fusiformis had sulfated galactofucan fractions using electrophoresis, which supported that the exist of galactosyl residue in F4 is not due to the contamination of galactan. We thus consider that $\mathrm{F} 4$ from $H$. fusiformis is sulfated galactofucan, and this is the first report to elucidate the structure of fucoidans containing high-fucose and sulfate from $\mathrm{H}$. fusiformis with an acidic extraction. The biological activities and interactions between the structure and activities of fucoidans containing high-fucose and ester sulfate from $H$. fusiformis are now under investigation. 


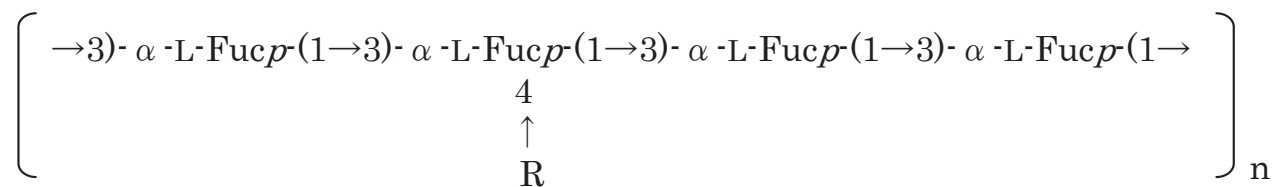

$$
\begin{array}{r}
\mathrm{R}=\alpha-\mathrm{L}-\mathrm{Fuc} p^{-}(1 \rightarrow 4)-\alpha-\mathrm{L}-\mathrm{Fuc} p^{-}(1 \rightarrow \quad(50 \% \mathrm{a}) \\
\text { or } \\
\alpha-\mathrm{D}-\mathrm{Gal} p^{-}(1 \rightarrow 4)-\alpha-\mathrm{D}-\mathrm{Gal} p^{-}(1 \rightarrow \quad(50 \% \mathrm{a})
\end{array}
$$

$58 \%^{\mathrm{a}}$ of hydroxyl group is sulfated.

a: molar ratio.

\begin{tabular}{|c|c|c|}
\hline Peak No. & Alditol & Relative mole ratio \\
\hline 1 & $2,3,4-\mathrm{Me}_{3}-\mathrm{Fuc} \quad$ (Non-reducing Fuc $\left.p\right)$ & 13 \\
\hline 2 & {$[\rightarrow 4)-\alpha-\mathrm{L}-\mathrm{Fuc} p-(1 \rightarrow]$} & 10 \\
\hline 3 & {$[\rightarrow 3)-\alpha-\mathrm{L}-\mathrm{Fuc} p-(1 \rightarrow]$} & 53 \\
\hline 4 & $2,3,4,6-\mathrm{Me}_{4}$-Gal (Non-reducing Gal $p$ ) & 5 \\
\hline 5 & {$[\rightarrow 3,4)-\alpha-\mathrm{L}-\mathrm{Fuc} p^{-}(1 \rightarrow]$} & 16 \\
\hline 6 & $2,3,6-\mathrm{Me}_{3}-\mathrm{Gal} \quad[\rightarrow 4)-\alpha-\mathrm{D}-\mathrm{Gal} p-(1 \rightarrow]$ & 5 \\
\hline
\end{tabular}

Fig. 7. Proposed structure of fucoidan fraction F4 from $H$. fusiformis.

Table 3. Methylated sugars derived from DeS-F4.

Acknowledgement We thank Yonabaru Nishihara Town Fisherman's Union for the gift of a $H$. fusiformis sample.

\section{References}

Baba, M., Snock, R., Pauwels, R. and DeClercq, E. (1988). Sulfated polysaccharide are potent and selective inhibitors of various enveloped viruses, including herpes simplex virus, cytomegalovirus, vesicular stomatitis virus and human immunodeficiency virus. Antimicrob. Agents Chemother., 32, 1742-1745.

Berteau, O. and Mulloy, B. (2003). Sulfated fucans, fresh perspectives: structures, functions, and biological properties of sulfated fucans and an overview of enzymes active toward this class of polysaccharide. Glycobiology, 13, 29R-40R.

Bilan, M. I., Grachev, A. A., Ustuzhanina, N. E., Shashkov, A. S., Nifantief, N. E. and Usov, A. I. (2002). Structure of a fucoidan from the brown seaweed Fucus evanescens C. Ag. Carbohydr. Res., 337, 719-730.

Bilan, M. I., Grachev, A. A., Shashkov, A. S., Nifantiev, N. E. and Usov, A. I. (2006). Structure of a fucoidan from the brown seaweed Fucus serratus L. Carbohydr. Res., 341, 238-245.

Chevolot, L., Faucault, A., Kervarec, N., Sinquin, C., Fischer, A. M. and Boisson-vidal, C. (1999). Further data on the structure of brown seaweed fucans: Relationships with anticoagulant activity. Carbohydr. Res., 319, 154-165.

Chizhov, A. O., Dell, A., Morris, H. R., Haslam, S. M., McDowell,
R. A., Shashkov, A. S., Nifant'ef, N. E., Khatuntseva, E. A. and Usov, A. I. (1999). A study of fucoidan from the brown seaweed Chorda filum. Carbohydr. Res., 320, 108-119.

Daniel, R., Chevolot, L., Carrascal, M., Tissot, B., Mourao, P. A. S. and Abian, J. (2007). Electrospray ionization mass spectrometry of oligosaccharides derived from fucoidan of Ascophyllum nodosum. Carbohydr. Res., 342, 826-834.

Doane, W. M. and Whistler, R. L. (1963). Comparison of the anticoagulant activity of three polysaccharide sulfates. Arch. Biochem. Biophys., 101, 436-438.

Dobashi, K., Nishino, T., Fujihara, M. and Nagumo, T. (1989). Isolation and preliminary characterization of fucose-containing sulfated polysaccharides with blood-anticoagulant activity from the brown seaweed Hizikia fusiforme. Carbohyd. Res., 194, 315-320.

Dodgson, K. S. (1961). Determination of inorganic sulphate in studies on the enzymic and non-enzymic hydrolysis of carbohydrate and other sulphate esters. Biochem. J., 78, 312-319.

Dubois, M., Gilles, K. A., Hamilton, J. K., Rebers, P. A. and Smith, F. (1956). Colorimetric method for determination of sugars and related substances. Anal. Chem., 28, 350-356.

Farias, W. R. L., Valente, A.-P., Pereira, M. S. and Maurão, P. A. S. (2000). Structure and anticoagulant activity of sulfated galactan. $J$. Biol. Chem., 275, 29299-29307.

Galambos, J. T. (1967). The reaction of carbazole with carbohydrate. Anal. Biochem., 19, 119-132. 
Itoh, H., Noda, H., Amano, H., Zhuang, C., Mizuno, T. and Itoh, H. (1993). Antitumor activity and immunological properties of marine algal polysaccharide, especially fucoidan, prepared from Sargassum thunbergii of Phaeophyceae. Anticancer Res., 13, 2045-2052.

Li, B., Wei, X.-J., Sun, J.-L. and Xu, S. Y. (2006). Structural investigation of a fucoidan containing a fucose-free core from the brown seaweed, Hizikia fusiformis. Carbohydr. Res., 341, 1135-1146.

Nagasawa, K., Inoue, Y. and Kawata, T. (1977). Solvolytic desulfation of glycosaminoglycuronan sulfates with dimethl sulfoxide containing water or methanol. Carbohydr. Res., 58, 47-55.

Nagumo, T. and Nishino, T. (1996). Fucan sulfates and their anticoagulant activities. in Polysaccharide in Medical Applications, S. Dumitrius, Ed., Marcel Dekker, New York, pp. 545-574.

Needs, P. W. and Selvendran, R. R. (1993). Avoiding oxidative degradation during sodium hydroxide / methyl iodine-mediated carbohydrate methylation in dimethyl sulfoxide. Carbohydr. Res., 245, 1-10.

Nishide, E., Anzai, H. and Uchida, N. (1987). A comparative investigation on the contents of fucose-containing polysaccharides from various Japanese brown algae. Nippon Suisan Gakkaishi, 53, 1083-1088 (in Japanese).

Nishino, T. and Nagumo, T. (1987). Sugar constituents and bloodanticoagulant activities of fucose-containing sulfated polysaccha- ride in nine brown seaweed species. Nippon Nōgeikagaku kaishi, 61, 361-363 (in Japanese).

Nishino, T., Takebe, Y. and Nagumo, T. (1994). Isolation and partial characterization of a novel $\beta$-D-galactan sulfate from the brown seaweed Laminaria angustata var. longissima. Carbohydr. Polym., 23, 165-173.

Ponce, N. M. A., Pujol, C. A., Damonte, E. B., Flores, M. L. and Stortz, C. A. (2003). Fucoidans from the brown seaweed Adenocystis utricularis: extraction methods, antiviral activity and structural studies. Carbohydr. Res., 338, 153-165.

Shibata, H., Iimuro, M., Uchida, N., Kawamori, T., Nagaoka, M., Uchiyama, S., Hashimoto, S., Yokokura, T., Sugimura, T. and Wakabayashi, K. (2003). Preventive effects of Cladosiphon fucoidan against Helicobacter pylori infection in Mongolian gerbils. Helicobacter, 8, 59-65.

Shiroma, R., Uechi, S., Taira, T., Ishihara, M., Tawata, S. and Tako, M. (2003). Isolation and characterization of fucoidan from Hizikia fusiformis (Hijiki). J. Appl. Glycosci., 50, 361-365.

Shiroma, R., Uechi, S., Tawata, S. and Tako, M. (2007). Isolation and characterization of alginate from Hizikia fusiformis and preparation of their oligosaccharides. J. Appl. Glycosci., 54, 85-90.

Tako, M., Yoza, E. and Tohma, S. (2000). Chemical characterization of acetyl fucoidan and alginate from commercially cultured Cladosiphon okamuranus, Bot. Mar., 43, 393-398. 